\title{
Ética discursiva y diversidad funcional
}

\author{
Discourse etbics and functional diversity
}

\author{
MANUEL APARICIO PAYÁ
}

Departamento de Filosofía - Universidad de Murcia. Consejería de Educación de Murcia

Artículo recibido: 14 de julio de 2017

Solicitud de revisión: 21 de septiembre Artículo aceptado: 4 de diciembre de 2017

\section{Resumen}

En este artículo hacemos un breve recorrido por algunas de las ideas fundamentales de la ética del diálogo (K.O. Apel, J. Habermas y A. Cortina) considerando que constituye un enfoque adecuado para afrontar las obligaciones de justicia con la totalidad de las personas con diversidad funcional. Nos basamos en que: $a$ ) la ética del diálogo mantiene el universalismo moral y político defendido por Kant, transformando su noción normativa de persona a partir de la idea de reconocimiento propuesta por Hegel, lo que permite sostener la perspectiva igualitaria de los derechos de todos; $b$ ) en su evolución, recoge las críticas planteadas desde el feminismo y el neoaristotelismo (Benhabib, Young, Nussbaum, MacIntyre) y concibe al sujeto moral como un ser corporal, lo que implica una concepción de la autonomía moral y política abierta a la vulnerabilidad corporal.

Palabras clave: ética discursiva, diversidad funcional, reconocimiento, vulnerabilidad y ética de la razón cordial.

\begin{abstract}
In this article we make a short exposure of some fundamental ideas of the ethics of dialogue (KO Apel, J. Habermas and A. Cortina) considering that it constitutes an adequate approach to face the obligations of justice with all the people with functional diversity. We base ourselves on the fact that a) the ethics of dialogue maintains the moral and political universalism defended by Kant, transforming his normative notion of person from the idea of recognition proposed by Hegel, which allows to maintain the egalitarian perspective of the rights of all; B) In its evolution, it takes the criticisms raised from feminism and neoaristotelism (Benhabib, Young, Nussbaum, MacIntyre) and conceives the moral subject as a corporeal being, this implies a conception of moral and political autonomy open to the body vulnerability.
\end{abstract}

Keywords: Discourse ethics, functional diversity, recognition, vulnerability and ethics of cordial reason. 


\section{INTRODUCCIÓN}

La filosofía moral y política de las últimas décadas se ha ocupado de la cuestión de la justicia con las personas con diversidad funcional, influida por las reivindicaciones sociales que afectaban a tales personas y por la aparición del campo teórico de los denominados «estudios sobre la discapacidad». De especial relevancia en esta temática es la publicación en 1999, por parte de Alasdair MacIntyre, del libro Animales racionales y dependientes, o la aparición, en 2006, de la obra de Martha Craven Nussbaum Las fronteras de la justicia. ${ }^{1}$ Se trata de obras que, con los pertinentes matices y con sus diferencias, cabe encuadrar en la tradición neoaristotélica. No ocurre igual con otra de las grandes tradiciones contemporáneas de filosofía moral y política: la ética discursiva no se ha ocupado sistemáticamente de la cuestión. No obstante, Sheila Benhabib sugiere en varias notas a pie de página que la ética dialógica permite conceptualizar las obligaciones morales y políticas que tenemos hacia aquellas personas que apenas son capaces de habla y acción. En su obra El ser y el otro en la ética contemporánea (Benhabib, 2006a: 74) alude a la dimensión moral del cuidado e indica que dichas obligaciones se derivan de la existencia de una continuidad entre el discurso argumentativo y la comunicación no lingüística - gestos, signos corporales, etc.- que pueden tener, por ejemplo, las personas con diversidad mental o cognitiva extrema. En consecuencia, tratándose de miembros de la comunidad de comunicación, hemos de presuponer siempre, contrafácticamente, la igualdad de derechos. En una segunda nota a pie de página incluida en Las reivindicaciones de la cultura (Benhabib, 2006b: 42-43) entiende que todas las personas con diversidad funcional, en tanto que ya siempre forman parte de la comunidad de discurso, tienen «personalidad moral y legal», aunque no todas posean «agencia moral y legal», ya que esta es variable, dependiendo del tipo y grado de diversidad funcional. En dicha nota tiene en cuenta, además de la dimensión del cuidado, las reivindicaciones de justicia realizadas por el movimiento social de personas con diversidad funcional. En tal sentido, Benhabib señala que las normas relativas a la inclusión social (accesibilidad, empleo, etc.) están sujetas también a validación discursiva; considera, no obstante, que las obligaciones de carácter moral y político hacia tales personas se deri-

1 Es significativo que el año de publicación de esta obra coincida con la aprobación, por parte de la ONu, de la Declaración Internacional de los Derechos de las Personas con Discapacidad. 
van también, más allá del ámbito del discurso, a partir del mundo de la vida.

En este artículo pretendemos desarrollar estas sugerencias de Benhabib, recurriendo para ello al pensamiento de Apel y de Habermas, como fundadores de este enfoque, así como a la «ética de la razón cordial» de la profesora Adela Cortina, como variación de la ética discursiva. Nuestro objetivo será mostrar que este enfoque ético, encuadrado en la tradición kantiana, permite fundamentar las obligaciones de cuidado y de justicia que tenemos con las personas con diversidad funcional, incluso con aquellas que tienen circunstancias fácticas que les impiden la expresión y/o la comprensión lingüística.

\section{LA DIVERSIDAD FUNCIONAL DESDE LA ÉTICA DISCURSIVA DE K. O. APEL}

Como se sabe,Apel realiza la transformación semiótico-trascendental de la filosofía trascendental de Kant. ${ }^{2}$ La introducción del "giro lingüístico» implica un cambio de paradigma desde una filosofía del sujeto, concebido como conciencia, a una filosofía centrada en la intersubjetividad propia del lenguaje. El pensamiento tiene un carácter lingüístico, lo cual implica la superación del solipsismo, ya que, según Apel -que, como es sabido, sigue en este punto a Wittgenstein - no hay «lenguaje privado»: el uso de un lenguaje supone el manejo de un conjunto de reglas, y no existen reglas que puedan ser usadas por un único individuo. Desde ese punto de vista, el pensamiento y la acción con sentido están mediados por un conjunto de signos y estos, en virtud de la dimensión pragmática del lenguaje, remiten a una comunidad real de comunicación. Por otra parte, Apel considera que la argumentación es el «último» juego lingüístico de toda la cadena, que tiene que presuponerse o anticiparse cuando se aspire a argumentar o actuar con sentido. Por eso, la argumentación - sea pública o tenga lugar internamente en el pensamiento- constituye para Apel «lo irrebasable» (Apel, 1985a: II, 211). La argumentación es el «juego lingüístico trascendental» y remite a la comunidad ideal e ilimitada de comunicación. Ahora

2 Juan Carlos Siurana (2003) entiende que este proyecto transformativo corresponde a una segunda etapa de su pensamiento, caracterizada por ofrecer un criterio que permita juzgar acerca del progreso y por proponer la reflexión como base de la emancipación de la humanidad. A esta etapa pertenece su artículo "El a priori de la comunidad de comunicación y los fundamentos de la ética". Para una panorámica general de la transformación de la filosofía en Apel, véase Smilg (2000). 
bien, Apel tiene una concepción amplia de lo que es un «argumento», irreductible al modelo canónico lógico-deductivo. Entiende como argumentos virtuales todas «las expresiones lingüísticas, e incluso todas las acciones con sentido y las expresiones humanas corporales (en la medida en que pueden ser verbalizadas)»(Apel, 1985a: II, 380). Apel recoge la idea de Wittgenstein de que las expresiones lingüísticas están entretejidas con acciones y expresiones corporales, es decir, con "formas de vida», lo que permite su verbalización. En tal sentido, puede decirse que el llanto de un niño que sufre o la inquietud que manifiesta un niño autista cuando se produce una alteración de sus rutinas, aunque no se expresen por medio del lenguaje, son también «argumentos». Desde ese punto de vista, las expresiones corporales de las personas con diversidad funcional que no pueden emplear ningún tipo de lenguaje también constituyen "pretensiones» de sentido y validez que, desde el punto de vista pragmático, requieren ser interpretadas para comprender las necesidades que expresan y para actuar con vistas a satisfacerlas. Para efectuar tal comprensión, el intérprete está obligado a adoptar lo que para él es una «situación vital extraña» (Apel, 1985a: II, 367) y, en tanto que ya siempre presupone el lenguaje, su interpretación está sujeta al «a priori del acuerdo» (Apel, 1985. II, 370). En consecuencia, el intérprete tiene que imaginar contrafácticamente las respuestas que darían las personas con diversidad funcional, en el caso de que no puedan usar ningún lenguaje o presenten dificultades cognitivas.

Tal continuidad entre los argumentos lógico-deductivos y los gestos corporales es la base apuntada por Benhabib para conceptualizar las obligaciones morales de cuidado con las personas con diversidad funcional. Rechaza así las críticas a la ética dialógica realizadas por quienes consideran que hay personas sin capacidad lingüística o que no pueden formular argumentos de tipo lógico, por lo que, en consecuencia, no podrían incluirse en la comunidad de comunicación. Hay una consecuencia que, desde el planteamiento de Apel, me parece relevante: al subrayar tal continuidad se pone de manifiesto la amplitud de lo humano que, como bien dice Benhabib, se extiende más allá del individuo adulto capaz de lenguaje y acción con sentido. La «forma humana de vida» (Apel, 1985a: II, 331), en el amplio espectro en que esta se manifiesta, está entretejida con el lenguaje, por lo que su comprensión remite a la comunidad real de comunicación. Esta comunidad es la que posibilita la comprensión del sentido de los argumentos virtuales; es la que permite comprender la especificidad de la «forma de vida» de las personas con diversidad funcional, que, incluso en situacio- 
nes de extrema vulnerabilidad, no es sino una forma de vida bumana. ${ }^{3}$ Puede decirse entonces que, para Apel, el lenguaje constituye lo humano en un doble sentido: tanto por el hecho de que un ser humano concreto pueda llegar a usarlo instrumentalmente, como también porque, en un sentido más básico, todo lo humano -incluidas también las manifestaciones de la corporalidad con diversidad funcional- se comprende a partir del lenguaje, es decir, desde la comunidad real de comunicación y, en último término, desde la comunidad ideal de comunicación. La pragmática trascendental apeliana tiene en cuenta no solo el a priori lingüístico, sino también el a priori de la corporalidad humana, «qua a priori del signo» (Apel \& Dussel, 2005: 327). A pesar del primado ontológico del cuerpo - sin cuerpo no hay lenguaje-, ambos tienen carácter apriorístico, es decir, se co-suponen ya siempre. De ahí que incluso los cuerpos con diversidad funcional que cuentan con circunstancias fácticas extremas también son signo de lo humano y, por tanto, también están constituidos lingüísticamente. La inserción de dichos cuerpos en el mundo humano, configurado por medio del lenguaje, supone la pertenencia de la totalidad de los seres humanos a la comunidad ideal de comunicación.

La reflexión trascendental apeliana llega a descubrir una norma ética fundamental, en la cual se redefine la noción normativa de persona de Kant:

todos los seres capaces de comunicación lingüística deben ser reconocidos como personas puesto que en todas sus acciones y expresiones son interlocutores virtuales, y la justificación ilimitada del pensamiento no puede renunciar a ningún interlocutor y a ninguna de sus aportaciones virtuales a la discusión (Apel, 1985a: II, 380).

Todo ser humano, tenga o no diversidad funcional, pueda o no usar el lenguaje, debe ser reconocido como persona por estar dotado - real o virtualmente- de competencia comunicativa. Aunque Apel no la desarrolla, en dicha definición se incluye también la idea de dignidad. ${ }^{4}$ En ese sentido, el reconocimiento de los seres humanos -incluidos todos aquellos con diversidad funcional- como personas, en tanto que son interlocutores reales o virtuales que pertenecen a la comunidad ideal de argumentación - moral y política - anticipada contrafácticamente, supone el reconoci-

3 Nussbaum considera que sigue siendo necesario dejar de ocultar los fenómenos humanos de la diversidad funcional y la dependencia, como paso previo al logro de una sociedad justa (Nussbaum, 2006).

4 En una obra posterior afirma: "Resulta, entonces, que las "relaciones recíprocas de reconocimiento" (Habermas) de nuestro argumentar actual sobre los problemas que están en discusión, incluyen también las bases indiscutibles de la dignidad humana y de los derechos humanos que pueden defenderse filosóficamente como universalmente válidos en un debate intercultural" (Apel, 2004: 226). 
miento de su dignidad. ${ }^{5}$ En este reconocimiento de la persona queda incluida su corporalidad - si bien en tanto que a priori del signo de lo humano- aunque Apel indica que la «interpelación del otro» a través de su corporalidad vulnerable ha de quedar incorporada como exigencia comunicable a través de la argumentación. ${ }^{6}$

En la comunidad ideal de comunicación se presupone que «todos los miembros se reconocen recíprocamente como interlocutores con los mismos derechos» (Apel, 1985a: II, 380). También deben ser reconocidas siempre «todas las exigencias virtuales de todos los miembros virtuales», es decir, todas las necesidades bumanas. En consecuencia, han de estar ya siempre incluidos todos los seres humanos con diversidad funcional, en tanto que personas, ${ }^{7}$ y el conjunto amplio y variado de sus necesidades atípicas (Nussbaum, 2007) que, como exigencias intersubjetivas, pueden, real o virtualmente, plantear:

El sentido de la argumentación moral podría expresarse adecuadamente en un principio que no es precisamente nuevo: todas las necesidades de los hombres, que puedan armonizarse con las necesidades de los demás por vía argumentativa, en tanto que exigencias virtuales, tienen que ser de la incumbencia de la comunidad de comunicación (Apel, 1985a: II, 404).

El universalismo de la norma fundamental propuesta por Apel avala, pues, la igualdad de derechos pragmáticos de todas las personas con diversidad funcional, que no deben ser excluidas de la argumentación de nor-

5 Michelini y Romero (2011) distinguen entre dignidad primordial (ser miembros - reales o virtuales - de la comunidad ideal de comunicación, y poder desempeñarse en la comunidad real de comunicación como interlocutor discursivo) y dignidad primigenia (propia de los interlocutores dialógicos de la comunidad real de comunicación). La primera no admite grados y está al margen de lo contingente, sin que pueda quedar lesionada por ninguna circunstancia azarosa — como, por ejemplo, la diversidad funcional. La dignidad primigenia es histórica y contingente, y puede quedar afectada por injusticias sociales o por insuficiencias materiales.

6 En su discusión con Dussel indica Apel que "lo irrebasable en el sentido trascendental no puede ser la vida o la existencia corporal, sea ésta tan fundamental en sentido ontológico como se quiera". Por eso, "la exigencia puramente fenomenológica de la "interpelación del Otro" [...] no puede quedar descartada como una exigencia [...] moralmente no obligatoria. Esto significa también, por supuesto, que "la interpelación del Otro" [...] debe hacerse valer por los propios afectados mismos o por sus abogados [...] en discursos sobre este tema" (Apel \& Dussel, 2005: 326-327).

7 Peter Singer considera que hay seres humanos - aquellos con diversidad intelectual o mental extrema- que no pueden ser considerados personas. Por contra, Cortina une la pertenencia a la comunidad humana y el carácter de persona de los seres humanos con diversidad funcional. Con independencia del grado de capacidad comunicativa que posea un ser humano, solo puede desarrollarla en la comunidad humana (Cortina, 2009a: 182). La ausencia de alguna capacidad - como la comunicativa - no es una característica positiva que sitúe a un ser humano en otra especie distinta, por lo cual existe la obligación de incluirla en la comunidad humana (Cortina, 2009b: 188-189). 
mas que les afectan ni ver postergadas sus necesidades específicas, en cuanto exigencias interpersonales comunicables, so pena de que dicha argumentación carezca de validez. Lo cual exige que, cuando una persona con diversidad funcional no esté en disposición de comunicar tales necesidades, se introduzca en el discurso la figura de la representación. Corresponderá al representante intervenir en el discurso en legítima defensa de los intereses de la persona representada, ${ }^{8}$ lo cual tendrá que quedar acreditado a través del intercambio de razones - en último término, en el proceso ilimitado de argumentación de la comunidad ideal de comunicación.

Por otra parte, Apel no concibe la ética del discurso como mera ética deontológica de principios sino, más bien, como una «ética de la responsabilidad». Esto significa, en primer lugar, que tiene en cuenta las consecuencias y subconsecuencias de la acción. Estas vendrán clarificadas atendiendo no solo a lo que determinen los individuos participantes en el discurso, sino también con la inclusión de las orientaciones empíricas de los expertos (Apel, 1985b: 236-237). La ética formal discursiva, a diferencia de la ética formal-monológica kantiana, proporciona el principio de una ética de la responsabilidad, que Apel toma del principio procedimental de universalización de normas mediante el discurso práctico de Habermas:

(U) Cualquier norma válida tiene que satisfacer la condición de que las consecuencias y subconsecuencias, que resulten previsiblemente de su seguimiento universal para satisfacer los intereses de cada individuo, puedan ser aceptadas sin coacción por todos los afectados (Apel, 1985b: 250).

Lo que propone Apel es transformar el imperativo categórico kantiano, como principio de universalización, bajo el criterio del principio de fundamentación (U), de forma que esta transformación refleje también este

8 MacIntyre considera que los requisitos de una adecuada representatividad son la amistad con el representado, la veracidad y el reconocimiento de las virtudes morales (MacIntyre, 2001). Rawls señala que la representación "debe guiarse por los principios de la justicia y por lo que se conoce acerca de los intereses más permanentes del individuo o por el cómputo de bienes primarios" (Rawls, 1979: 284-286). Inspirándose en Apel, Adela Cortina propone un ethos moral (Cortina, 1985: 75-77; 1990: 236-238). En la cuestión de la representación podría interpretarse este ethos del modo siguiente: $a$ ) autorrenuncia a los propios intereses, al menos para el afloramiento de los intereses del representado; $b$ ) reconocimiento de los derechos pragmáticos del representado — exponiendo y justificando sus necesidades atípicas; $c$ ) compromiso en la búsqueda de la verdad, y $d$ ) esperanza en el consenso definitivo acerca de las normas de justicia, como garantía crítica del consenso fáctico alcanzado. En otra obra posterior, Cortina corrige parcialmente los rasgos de este ethos, entre los que cabe destacar: $a$ ) la responsabilidad por las consecuencias —en este caso, en la vida del representado- previsibles de las decisiones tomadas, y b) la solidaridad — decidir teniendo en cuenta intereses generalizables, comunes a representado y representante- (Cortina, 1991). 
principio de responsabilidad en el seguimiento de normas. Dicha transformación podría formularse del modo siguiente:

\begin{abstract}
Obra según una máxima de la que puedas suponer en un experimento mental que las consecuencias y subconsecuencias, que seguirán previsiblemente de su seguimiento universal para la satisfacción de los intereses de cada uno de los afectados, pueden ser aceptadas sin coacción por todos los afectados en un discurso real; si pudiera llevarse a cabo con todos los afectados (Apel, 1985b: 251).
\end{abstract}

El discurso argumentativo, formulado como experimento mental, constituye también un principio de la acción individual. En relación con la obligación moral individual, Apel pone el ejemplo de alguien que tiene un tío enfermo y senil que ya no puede hablar. Para determinar las obligaciones morales hacia dicha persona habría que tener en cuenta tanto las necesidades de los afectados como la responsabilidad en el seguimiento de las normas aplicables a la situación. En dicho experimento mental el individuo ha de incorporar también las orientaciones empíricas de los expertos en el tema. Apel señala, no obstante, que aunque la ética discursiva pudiera aplicarse a dicho caso, también es posible y deseable que la acción realizada pudiera tener otro fundamento moral: el amor, la compasión, etc. Ahora bien, señala que cuando no existan estos motivos las obligaciones del cuidado pueden quedar bajo dicho principio de acción. La aplicación de tal principio tiene dos implicaciones relevantes respecto al cuidado: a) se reconoce a la persona con diversidad funcional, también a aquella en situación extrema y sin posibilidad de lenguaje, como un interlocutor virtual -como persona dotada de dignidad; $b$ ) se tienen en cuenta, como exigencias comunicables, las necesidades atípicas que tiene.

No obstante, Apel considera que la ética del discurso es una ética de la responsabilidad en un sentido más profundo que el referido a la acción individual en un contexto situacional: se preocupa también por la realización histórica de la aplicación del principio procedimental (U) (Apel, 1985b: 253-262). Este interés por la historia constituye el rasgo fundamental de un nuevo período en el pensamiento de Apel (Siurana, 2003: 4-5, 53-56). ${ }^{9}$ A su juicio, aquí se refleja la idea hegeliana de que la razón práctica - plasmada en las instituciones - es histórica, aunque también se refleja lo que Hegel ignora: que la realidad de las instituciones humanas también encierra irracionalidad. En ese sentido, quien argumenta en serio ha de

9 Siurana sitúa tal interés por la historia en una tercera etapa de su pensamiento. El artículo "La ética del discurso como ética de la responsabilidad. Una transformación postmetafísica de la ética de Kant" es característico de dicha etapa. 
anticipar contrafácticamente la comunidad ideal de comunicación -en la que se realiza $\mathrm{U}_{-}$, ha de presuponer las condiciones históricas y contingentes de la comunidad real de comunicación y, finalmente, ha de aceptar la obligación moral de ayudar a superar la diferencia entre las condiciones reales y las ideales. Dicha obligación moral conlleva el uso de las estrategias adecuadas - incluida la racionalidad estratégica- para la realización progresiva de la comunidad ideal de comunicación, con el límite que impone el «principio de conservación». De acuerdo con este principio, debería garantizarse la supervivencia de la comunidad real de comunicación y la "preservación de la "realidad racional" de nuestra tradición cultural». Lo que hay que conservar, pues, es la racionalidad existente en las instituciones sociales de un momento histórico contingente. Podríamos decir que, desde el punto de vista de la ética discursiva de Apel, habría que partir, en relación con el cuidado y la justicia con las personas con diversidad funcional, del momento histórico presente en el que, aun con cautelas, ha empezado -después de una larga postergación histórica- el reconocimiento de los derechos incluidos en la Convención de los Derechos de las Personas con Discapacidad, aprobada por la onu en 2006. Pero la ética discursiva no se conforma con ello si dichas instituciones no anticipan la «idea regulativa» de las condiciones ideales de comunicación (Apel, 1991: 181-184).

\section{2. ÉTICA DEL DISCURSO Y VULNERABILIDAD CORPORAL EN J. HABERMAS}

Al igual que Apel, la ética del discurso habermasiana, como ética formalprocedimental, recurre a una idealización - la situación ideal de habla- de las condiciones en que se produce la justificación de las normas. En la obra Conciencia moral y acción comunicativa plantea que, en tal situación, caracterizada por la universalidad y la reciprocidad, debe producirse el reconocimiento simétrico de todos los interlocutores válidos, con independencia de las asimetrías fácticas que puedan presentar. Lo cual exige que todos los afectados puedan considerarse como participantes en el discurso; que se tenga en cuenta que puedan defender sus intereses, $y$, finalmente, que sea posible que pudieran dar su aprobación a dicha norma, garantizando así su validez. Desde ese punto de vista, la comunidad moral es una "comunidad inclusiva», en la medida en que no excluye a ningún interlocutor válido (a ninguna persona). Las normas morales aceptadas 
como válidas en la comunidad moral han de cumplir un doble requisito: a) De acuerdo con los postulados de la ética discursiva, se ajustan a (D) (Habermas, 2000: 36), es decir, para ser una norma válida tendría que poder recibir la aquiescencia de todos los afectados tan pronto estos participasen en un discurso práctico, y b) las normas válidas de acuerdo con (D) han de atender a la diversidad de intereses y de perspectivas interpretativas (Habermas, 2009: 78-79), de forma que, teniendo sensibilidad con situaciones individuales, no nivele ni margine ni excluya las voces de las minorías sociales - como en el caso de las personas con diversidad funcional. Lo que propone Habermas es la adopción de una igualdad no homogeneizadora, de una igualdad abierta a la «diferencia» (Habermas, 2008). La propuesta de Habermas, que puede ser interpretada como un ideal regulativo (Velasco, 2003: 43-44), apunta a disponer de un criterio para la crítica de todas aquellas normas que afecten a las personas con diversidad funcional, en la medida en que sus voces - o las de quienes actúan como sus representantesno sean tenidas en cuenta, o no queden atendidos sus intereses, armonizados con los intereses de otros grupos sociales a través de la búsqueda y de la aceptación de los mejores argumentos.

Otro foco de interés para el tema que nos ocupa lo constituyen escritos como Entre naturalismo y religión o El futuro de la naturaleza buma$n a$, en los que Habermas sobrepasa el plano discursivo-procedimental, con una concepción idealizada de la persona como interlocutor válido, acercándose a la dimensión antropológica de la moral a partir de la caracterización fenomenológica de la persona como ser corporal. Desde esta óptica, Habermas concibe la moral como un mecanismo protector, tanto de los avatares que puedan sucederle al individuo en el proceso de socialización, como de la vulnerabilidad antropológica a la que está abierta la subjetividad encarnada. Si anteriormente Habermas sostiene una diluida concepción antropológica centrada en la capacidad de comunicación lingüística humana (Velasco, 2003: 46), consolidada a través del proceso socializador, en estas obras se produce un cambio que entendemos relevante: los sujetos que emergen con una identidad propia a través del proceso de socialización en el medio lingüístico son sujetos encarnados. ${ }^{10}$ Desde el momento mismo del nacimiento, el organismo animal de la especie humana se inserta en un conjunto de relaciones sociales y, a través de una cultura pública constituida lingüísticamente, puede llegar a convertirse en persona (Ha-

10 Dicho cambio tiene lugar en un contexto en el que, desde planteamientos neoaristotélicos -MacIntyre, Nussbaum - se venía remarcado el carácter constitutivamente corporal del ser humano y la importancia moral de la vulnerabilidad corporal. 
bermas, 2009: 51-52). La persona emerge, pues, del continuum orgánicosocial. El punto de partida de esta concepción habermasiana es el dato antropológico, que retoma de autores como Plessner, Arnold Gehlen o George H. Mead, de que el ser humano es un ser inacabado «en un sentido biológico y necesita la ayuda, el respaldo y el reconocimiento de su entorno social toda la vida». Al venir al mundo de forma desvalida, necesita un tiempo extenso de crianza cuidadosa bajo la protección familiar y del conjunto de la sociedad. Ahora bien, Habermas aclara que, a diferencia de las ideas antropológicas de Gehlen, lo más relevante no son las debilidades biológicas propias de los seres humanos - deficiencias en la dotación genética, riesgos del largo período de crianza, etc. - sino la vulnerabilidad social derivada del sistema sociocultural que ha de compensar aquella vulnerabilidad física, es decir, la vulnerabilidad derivada del proceso de socialización (Habermas, 2000: 19). Porque es la socialización, producida en un particular mundo de la vida compartido intersubjetivamente -gracias al lenguaje-, lo que permite la aparición de la individualidad:

La individuación espacio-temporal del género humano en sus distintos ejemplares no viene regulada ya por un equipamiento genético que se extienda sin solución de continuidad de la especie al organismo individual. Sucede más bien que los sujetos capaces de hablar y de actuar solamente se constituirán como individuos en tanto que, en calidad de su respectiva comunidad lingüística particular, crezcan y se integren en un mundo de la vida compartido intersubjetivamente (Habermas, 2000: 18).

Así pues, para Habermas, el proceso de individuación es, simultáneamente, un proceso de socialización. Esta socialización, inserta en el medio lingüístico, va tejiendo, a través de las interacciones sociales, un entramado simbólico de relaciones de reconocimiento recíprocas, del que surge el individuo singular, el miembro de la comunidad y la persona con una identidad propia (Habermas, 2009: 52-53). Habermas viene a conceptualizar aquellas intuiciones morales acerca del modo de contrarrestar la "vulnerabilidad» de la persona:

Desde un punto de vista antropológico la moral se puede entender como un dispositivo protector que compensa la vulnerabilidad inserta estructuralmente en las formas de vida socioculturales. Son vulnerables y están necesitados de protección en el sentido indicado los seres vivos que sólo se individúan por vía de socialización (Habermas, 2000: 18).

La protección frente a la fragilidad de la existencia corporal y frente a la vulnerabilidad social se encuentra en el comportamiento moral, en el establecimiento de normas válidas que regulen las relaciones intersubjeti- 
vas. Estas normas que regulan las relaciones interpersonales pueden entenderse como «una envoltura protectora porosa contra las contingencias a las que se ven expuestos el cuerpo (Leib) y la persona en él encarnada» (Habermas, 2009: 50). Habermas retoma la distinción fenomenológica de Plessner y entiende que la persona no solo tiene un cuerpo (Körper) sino que, de modo más básico, la persona es corporalidad (Leib). En ese sentido, Habermas concibe a la "persona» no solo como un «centro interior» (Habermas, 2000: 18) o subjetividad, dependiente de las relaciones intersubjetivas en un contexto social estructurado lingüísticamente, sino que también la concibe como una subjetividad encarnada corporalmente. La persona, como ya antes propusiera Apel, nos remite al reconocimiento recíproco y responde a la categoría «subjetividad/intersubjetividad» (Cortina, 1997: 234). De aquí proviene el doble peligro que acecha a la persona: la vulnerabilidad física, derivada de su carácter encarnado, y la vulnerabilidad simbólica, propia de una subjetividad singular surgida a través del proceso de socialización. La moral constituye un mecanismo protector frente al daño a la integridad corporal - con independencia de que este pueda ser provocado, por acción u omisión, o pueda provenir de la propia fragilidad corporal- como frente al daño que pueda causarse a la identidad, en tanto que esta se configura intersubjetivamente. En ese sentido, la moral universalista protege a todos los seres humanos, en tanto que estos tienen potencialmente el poder de razonar propio de la especie, desarrollado lingüísticamente en el seno de una particular comunidad social. Habermas entiende, recogiendo una cita de $M$. Seel, que la moral universalista se ocupa de todos los seres humanos sin excepción -incluidas, por tanto, las personas con diversidad funcional que no desarrollen el lenguaje y el razonamiento-, en tanto que pueden vivir una vida personal, con independencia de que fácticamente la puedan vivir. En tal sentido, el núcleo de la moral universalista consiste en «tratar a los seres humanos como seres humanos» (Habermas, 2009: 52). Lo cual implica un doble aspecto: tanto el trato justo con la persona - el trato igualitario en las relaciones de reconocimiento recíproco de personas que actúan comunicativamente- como el trato solidario y cuidadoso en la comunidad en la que esta se inserta - de la que depende la formación y estabilización de su identidad, ya que está formada intersubjetivamente.

En El futuro de la naturaleza bumana, obra en la que apela a la ética de la especie o autocomprensión antropológica de personas que actúan autónomamente - esto es, libre y responsablemente-, Habermas acepta la crítica de Nussbaum a la noción kantiana de autonomía de la persona. En 
tanto que la persona es, a la vez, el ser humano capaz de racionalidad comunicativa y una «subjetividad/intersubjetividad» encarnada, la autonomía tiene que ser concebida al modo de una «conquista precaria de las existencias finitas», por estar sujeta a la fragilidad corporal y a la dependencia social. Se trata, pues, de una autonomía finita que requiere protección moral, tanto para que pueda surgir como para que sea apoyada cuando quede menguada o, incluso, cuando desaparezca. No obstante, la respuesta de Habermas es que únicamente el ejercicio de la autonomía para el establecimiento discursivo de las normas morales, con vistas a la regulación de las relaciones intersubjetivas de reconocimiento recíproco, es lo que puede, finalmente, proteger dicha vulnerabilidad - tanto física como simbólica. Por otra parte, considera que el concepto de dignidad bumana, propio de una moral universalista posconvencional, debe entenderse ahora como la simetría existente en el seno de las relaciones interpersonales de reconocimiento recíproco, es decir, en el trato igualitario y respetuoso dado entre los interlocutores participantes en la acción comunicativa. Y, en último término, entre todos los miembros participantes de la comunidad moral, la cual está inserta en formas de vida comunicativas concretas. La dignidad humana no constituye, para Habermas, un rasgo ontológico de una pretendida esencia humana, sino que es aquella inviolabilidad práctica que cobra sentido en las relaciones intersubjetivas de reconocimiento recíproco, en el trato igualitario y respetuoso que se dan entre sí las personas. Dicho trato no pierde sentido ni siquiera en situaciones fácticas de extrema vulnerabilidad corporal.

\section{RECONOCIMIENTO CORDIAL, DIGNIDAD Y VULNERABILIDAD EN A. CORTINA}

La propuesta de una «ética de la razón cordial» de Cortina pretende ser una "versión cálida» de la ética del discurso, que supera la racionalidad formal recurriendo a una racionalidad impura, a una razón encarnada. Sin renunciar a la vinculación lingüística entre los seres humanos, su ética ahonda en las consecuencias - no desarrolladas por Habermas- de tener una razón humana anclada en la corporalidad: Cortina descubre un vínculo compasivo sin el cual no habría interés en participar en argumentaciones que buscan la justicia con las personas con diversidad funcional. La ética cordial no se ciñe exclusivamente al aspecto lógico-formal de la argumentación, sino que, además de tener en cuenta otros tipos de comunicación 
- los testimonios, las narraciones o las historias de vida- en apoyo de la argumentación (Cortina, 2009a: 207), se preocupa también por sus aspectos sentientes:

Su nombre será ética de la razón cordial, ethica cordis, empeñada en mostrar cómo el vínculo comunicativo no sólo cuenta con una dimensión argumentativa, no sólo revela una capacidad para argumentar sobre lo verdadero y lo justo, sino que cuenta también con una dimensión cordial y compasiva, sin la cual no hay comunicación. O mejor dicho, una ética empeñada en mostrar que para argumentar con éxito sobre lo justo ba de bundir sus raíces en su vertiente cordial y compasiva (Cortina, 2009a: 191).

Desde esta concepción ética se concibe la persona como un ser dotado de corporalidad:

Son personas los seres dotados de competencia comunicativa, es decir, los interlocutores válidos, que se reconocen mutuamente no sólo razón capaz de argumentar, sino también razón encarnada en un cuerpo, razón humana (Cortina, 2009b: 225).

Por eso mismo, el reconocimiento racional-sentiente del otro como persona supone, simultáneamente, el reconocimiento de su corporalidad y, por tanto, de su vulnerabilidad - a la vez que el reconocimiento de nuestra propia vulnerabilidad. Cortina distingue dos tipos de reconocimiento (Cortina, 2005: 152-153). El primero procede de la tradición socrática y continúa también en la ética del diálogo: es el reconocimiento de la persona, en tanto que - real o virtualmente - es un interlocutor válido. En esta forma de reconocimiento se descubre una vinculación, una ligadura (ligatio), que genera una obligación (obligatio), entre quienes son virtuales participantes en el diálogo - con la totalidad de la comunidad de comunicación en último término - en el que se comprueba la justicia de las normas. Pero existe una segunda forma de reconocimiento, que esta pensadora considera más originaria que la anterior, que tiene su origen en la tradición judeocristiana de la Alianza -aunque hoy está secularizada. Consiste en el reconocimiento del otro como persona que me pertenece y a la que pertenezco, en tanto que es alguien que es «carne de mi carne y hueso de mi hueso» (Gén. 2: 23): alguien a quien percibo gozosamente como un semejante a mí, como «otro yo» con el que puedo entablar una relación de igual a igual, una relación muy distinta a la que puede entablarse con otros animales o con las cosas. Este segundo tipo de reconocimiento, más originario que el anterior pero vinculado con él - este cuerpo ajeno que reconozco como semejante al mío es alguien con quien es probable que pueda comunicarme lingüística y argumentativamente-, consiste en la experien- 
cia de un vínculo vivencial, en la ligadura experiencial entre seres humanos. Es decir, entre aquellos que se reconocen como personas porque, teniendo en común un mismo tipo de corporalidad -compartiendo la corporalidad bumana -, comparten su vida con otras personas, con comunidades de personas o con el conjunto de personas que forman parte de la bumanidad (Cortina, 2005: 170-171). De esta ligadura es de la que surgen las correspondientes obligaciones respecto al trato que debe tener cualquier persona:

\begin{abstract}
El reconocimiento recíproco de quienes se sienten carne de la misma carne, hueso del propio hueso, alienta esos deberes de justicia, que exigen imperiosamente satisfacer necesidades convertidas en derechos, y abre el camino del diálogo y de la necesidad de una organización política que funcione de forma deliberativa, aprovechando el potencial comunicativo, que debería ser el auténtico poder de la vida compartida (Cortina, 2005: 177).
\end{abstract}

En esta ligatio más originaria no importa si la relación entre ambos seres humanos es simétrica o asimétrica, no importa que se trate de una persona con una corporalidad que tiene diversidad funcional.A esta segunda forma de reconocimiento es a la que Cortina denomina «reconocimiento cordial» o «reconocimiento compasivo» (Cortina, 2009a: 191), pues es una forma de reconocimiento basada en la compasión mutua entre seres humanos que se sienten obligados a darse apoyo mutuo - es decir, en tanto que son inter-dependientes - para sacar adelante sus proyectos de vida digna de ser vivida. Es un reconocimiento «experiencial» ${ }^{11}$ que se produce en el encuentro intercorporal entre seres humanos que se reconocen "personas». De la referencia a esta forma de reconocimiento puede extraerse una importante consecuencia: no es única ni prioritariamente la continuidad entre el discurso y las formas de comunicación - los gestos- que no siguen el modelo lógico-deductivo lo que permite derivar las obligaciones morales que tenemos con las personas con diversidad funcional que, por sus circunstancias fácticas, no pueden usar el lenguaje; es, más bien, esta vinculación experiencial-cordial con ellas -formando un «nosotros»- lo que constituye la fuente fundante de la que se derivan dichas obligaciones morales y jurídicas.

11 "Pues no siempre estamos en razón, ni en diálogo, ni en reflexión, pero sí siempre en la experiencia" (Conill, 1991: 163). Desde la concepción de la razón experiencial —que combina logos y experiencia- defendida por Conill, el cuerpo ya no se concibe como un mero a priori, sino que abre un ámbito experiencial más sensible a situaciones vividas por los sujetos sufrientes. Estamos, pues, ante una ética discursivo-experiencial y ante una "subjetividad/intersubjetividad" vital $-\mathrm{y}$ no solo reflexivo-formal- (Conill, 2006: 274-280). 
Entre ambas formas de reconocimiento se establece, según la profesora Cortina, una relación de complementariedad, pues la primera forma de reconocimiento descansa en la segunda: sin el reconocimiento cordial no es posible que se produzca un diálogo en serio entre las personas para determinar las normas comunes de justicia. Sin ese vínculo de co-pertenencia mutua vital es difícil que se produzca el reconocimiento mutuo en tanto que participantes en un diálogo para el establecimiento de tales normas. Sin tener en cuenta "qué experiencias vitales se encierran en las biografías únicas e irrepetibles», recurriendo a narraciones, testimonios e historias de vida, no podrá descubrirse, en el intercambio dialógico de argumentos, aquello que es justo (Cortina, 2009a: 206-207). Para determinar, a través de la argumentación, lo que es justo, se necesita contar con una razón cordial o compasiva que nos permita captar el sufrimiento de otros, iluminar zonas de injusticia y desarrollar la voluntad de justicia. ${ }^{12}$ Para ello, se ha de contar con

capacidad de estimar valores, con un sentir común que les permita sintonizar con los demás afectados, con narraciones suficientes como para comprender la fuerza de los argumentos, con la capacidad de reconocer al otro en su alteridad y de construir la propia identidad moral, con un carácter forjado día a día para intentar descubrir el mejor argumento, y con un profundo sentido de la compasión que brota del reconocimiento recíproco de los que se saben, no sólo interlocutores válidos, sino carne de la misma carne y hueso del mismo hueso (Cortina, 2009a: 196).

Es la capacidad de valorar la que puede llevar a la razón cordial a descubrir el valor absoluto de quienes son reconocidos como personas, es decir, la que nos permite apreciar y degustar el valor de la dignidad de toda persona, sin importar sus características corporales o mentales. La dignidad de todos y cada uno de los seres humanos, reconocidos como personas, no está dada ontológicamente, sino que, a partir de la capacidad de estimar, tiene que ser reconocida por otros seres humanos (Cortina, 2009b: 202). Así pues, para Cortina, la capacidad de estimar valores es la base para que pueda surgir el reconocimiento de la dignidad intrínseca de la persona. Dicho reconocimiento es el que permite, a su vez, que un ser humano cobre conciencia de que tiene una vida digna: digna de ser vivida en condiciones de humanidad. Y, en último término, el «reconocimiento recíproco de la igual dignidad» constituye el fundamento de una teoría de

12 La compasión, fomentada a través de la educación y la creación de un entramado institucional de apoyo justo a las personas con diversidad funcional, es lo que posibilita luchar contra la estigmatización de este grupo de personas, en muchas ocasiones pertenecientes a los peor situados en la sociedad (Cortina, 2017). 
la justicia (Cortina, 2011: 148). De ahí que pueda decirse, con Cortina, que el trato justo con cualquier persona con diversidad funcional tiene su fundamento en el reconocimiento de su igual dignidad. De este reconocimiento cordial de la igual dignidad se derivan una serie de exigencias, extensibles a todos los seres humanos:

no instrumentalizarle ni dañarle, empoderarle en la medida de lo posible, siempre que ello no suponga dañar a otros; estructurar de tal modo las instituciones y organizaciones sociales que pueda participar en sus beneficios de forma equitativa, teniendo como referencia los intereses universalizables; tomar las decisiones teniendo en cuenta dialógicamente a los afectados por normas de justicia (Cortina, 2009a: 223).

Por otra parte, la justicia cordial brota de la compasión. A su juicio, se trata de una compasión que no significa que quien compadece se sitúa en un plano superior al compadecido, adoptando una actitud paternalista hacia él. Se trata, más bien, de una compasión igualitaria, conectada al reconocimiento de la dignidad de un ser que es, a la vez, autónomo y vulnerable (Cortina, 2010: 102). Un ser que, incluso en situaciones fácticas de extrema vulnerabilidad corporal, no cabe situar allende las fronteras del ámbito personal (Cortina, 2009b); que pertenece al «nosotros» de la comunidad moral y política que ha de determinar también, recurriendo finalmente a discursos argumentativos - con la participación directa, apoyada o con representante, de las personas con diversidad funcional-, la validez de las normas de justicia que nos afectan a todos.

\section{CONCLUSIÓN}

Comenzaba el artículo indicando que la ética discursiva apenas se ha ocupado de la cuestión de la justicia con las personas con diversidad funcional. No obstante, recogiendo las sugerencias de Benhabib, hemos mostrado que este enfoque ético, continuando el universalismo de la ética kantiana, fundamenta las obligaciones que tenemos con la totalidad de las personas con diversidad funcional. En tal sentido, la transformación dialógica de la teoría moral kantiana llevada a cabo por Apel y Habermas conduce al establecimiento de un procedimiento intersubjetivo para fundamentar la validez incondicional de las normas que expresan obligaciones hacia las personas con diversidad funcional. El enfoque procedimental de las normas de trato justo debido a tales personas exige la inclusión igualitaria de todos los afectados que pudieran, real o virtualmente, participar en 
la situación idealizada de discurso y dar su consentimiento a estas. La inclusión de las personas con diversidad funcional, también la de aquellas en situación extrema, y de la totalidad de las exigencias que, real o virtualmente, pudieran plantear, supone su reconocimiento como interlocutores válidos - personas-, en algunos casos en virtud de la continuidad existente entre la comunicación gestual y la argumentación discursiva. En tales casos, se necesita contar con los representantes de tales personas para que se expresen sus intereses, con el fin de que tales normas tengan validez.

La ética cordial de Cortina reconoce también que el discurso argumentativo inclusivo, de acuerdo a condiciones lo más próximas posible a la simetría, ha de tener la última palabra a la hora de determinar la justicia de las normas que afectan a las personas con diversidad funcional. No obstante, esta autora extrae todas las consecuencias de entender a los sujetos como seres corporales que reconocen a los demás sujetos como personas con igual corporalidad, con las que se saben vinculadas en igual dignidad y vulnerabilidad. Dicha vinculación, que exige ir más allá del establecimiento puramente racional-procedimental de normas, nos abre al reconocimiento compasivo de los otros, en virtud de la estimación de valores anclada en la corporalidad. Esa vinculación, previa a la vinculación discursiva, supone que la inclusión igualitaria en la comunidad moral-discursiva, apoyada en la continuidad entre la gestualidad y la argumentación, tiene su fundamento en el reconocimiento compasivo de la igual dignidad de todas las personas con diversidad funcional. La estimación de tal valor es lo que hará, según Cortina, que se establezcan discursos - en los que tales personas habrán de participar igualitariamente, directamente, con asistencia o con representación - tendentes a fijar normas justas que favorezcan el empoderamiento de las diversas capacidades para que, a su vez, puedan participar en ellos.

\section{BIBLIOGRAFÍA}

Apel, Karl O. (1985a). La transformación de la filosofía, I y II. Madrid: Taurus.

Apel, Karl O. (1985b). ¿Límites de la ética discursiva? En Cortina, Adela, Razón comunicativa y responsabilidad solidaria (233-262). Barcelona: Sígueme. 
Apel, Karl O. (1991). La ética del discurso como ética de la responsabilidad. Una transformación posmetafísica de la ética de Kant. En Teoría de la verdad y ética del discurso (147-184). Barcelona: Paidós/ICE-UAB.

Apel, Karl O. (2004). ¿Disolución de la ética del discurso? Acerca de la diferenciación del discurso en la obra de Habermas Facticidad y Validez. En Smilg, Norberto (ed.). Apel versus Habermas. Elementos para un debate. Granada: Comares.

Apel, Karl O. \& Dussel, Enrique (2005). Ética del discurso y ética de la liberación. Madrid:Trotta.

Benhabib, Sheila (2006a). El otro generalizado y el otro concreto. En $\mathrm{El} \mathrm{ser}$ $y$ el otro en la ética contemporánea. Barcelona: Gedisa.

Benhabib, Sheila (2006b). Las reivindicaciones de la cultura: igualdad $y$ diversidad en la era global. Buenos Aires: Katz.

Conill, Jesús (1991). El enigma del animal fantástico. Madrid:Tecnos.

Conill, Jesús (2006). Ética bermenéutica. Madrid:Tecnos.

Cortina, Adela (1985). Razón comunicativa y responsabilidad solidaria. Barcelona: Sígueme.

Cortina, Adela (1990). Ética sin moral. Madrid:Tecnos.

Cortina, Adela (1991). Una ética política contemplada desde el ruedo ibérico. En Apel, Karl O, Cortina, Adela, De Zan, Julio, \& Michelini, Dorando (eds.). Ética comunicativa y democracia (219-240). Barcelona: Crítica.

Cortina, Adela (1997). Ética aplicada y democracia radical. Madrid:Tecnos.

Cortina, Adela (2009a). Ética de la razón cordial. Oviedo: Ediciones Nobel.

Cortina, Adela (2009b). Las fronteras de la persona. Madrid:Taurus.

Cortina, Adela (2010). Justicia cordial. Madrid:Trotta.

Cortina, Adela (2011). Neuroética y neuropolítica. Madrid:Tecnos.

Cortina, Adela (2017). Aporofobia, el rechazo al pobre. Barcelona: Paidós.

Habermas, Jürgen (2000). Aclaraciones a la ética del discurso. Madrid: Trotta.

Habermas, Jürgen (2008). La inclusión del otro. Barcelona: Paidós.

Habermas, Jürgen (2009). El futuro de la naturaleza bumana. Barcelona: Paidós.

MacIntyre, Alasdair (2001). Animales racionales y dependientes. Barcelona: Paidós.

Michelini, Dorando \& Romero, Eduardo (2011). Persona humana y dignidad. Una perspectiva ético-discursiva. Revista de Filosofía Universidad Costa Rica, L (127-128), 141-153. 
Nussbaum, Martha Craven (2006). El ocultamiento de lo bumano: repugnancia, vergüenza y ley. Madrid: Katz Barpal.

Nussbaum, Martha Craven (2007). Las fronteras de la justicia. Barcelona: Paidós.

Rawls, John (1979). Teoría de la justicia. Madrid: FCE.

Singer, Peter (1984). Ética práctica. Barcelona:Ariel.

Singer, Peter (2003). Desacralizar la vida bumana. Ensayos sobre ética. Madrid: Cátedra.

Siurana, Juan Carlos (2003). Una brújula para la vida moral. La idea de sujeto en la ética del discurso de Karl-Otto Apel. Granada: Comares.

Smilg, Norberto (2000). Consenso, evidencia y solidaridad. La teoría de la verdad de K. O. Apel. Granada: Comares.

Velasco, Juan Carlos (2003). Para leer a Habermas. Madrid:Alianza Editorial. 